\title{
Alteration of Leaf Surface Structures of Poplars under Elevated Air Temperature and Carbon Dioxide Concentration
}

\author{
Ki Woo Kim*, Chang Young Oh$^{1}$, Jae-Cheon Lee ${ }^{1}$, Solji Lee, Pan-Gi Kim* \\ School of Ecology and Environmental System, Kyungpook National University, Sangju 742-711, Korea \\ ${ }^{1}$ Department of Forest Genetic Resources, Korea Forest Research Institute, Suwon 441-350, Korea
}

*Correspondence to: Kim KW,

Tel: +82-54-530-1246

Fax: +82-54-530-1248

E-mail: kiwoo@knu.ac.kr

Kim PG,

Tel: +82-54-530-1242

Fax: $+82-54-530-1248$

E-mail: pgkim@knu.ac.kr

Received August 18, 2013

Revised September 11, 2013

Accepted September 16, 2013
Effects of elevated air temperature and carbon dioxide $\left(\mathrm{CO}_{2}\right)$ concentration on the leaf surface structures were investigated in Liriodendron tulipifera (yellow poplar) and Populus tomentiglandulosa (Suwon poplar). Cuttings of the two tree species were exposed to elevated air temperatures at $27 / 22^{\circ} \mathrm{C}$ (day/night) and $\mathrm{CO}_{2}$ concentrations at $770 / 790 \mathrm{ppm}$ for three months. The abaxial leaf surface of yellow poplar under an ambient condition $\left(22 / 17^{\circ} \mathrm{C}\right.$ and $\left.380 / 400 \mathrm{ppm}\right)$ had stomata and epicuticular waxes (transversely ridged rodlets). A prominent increase in the density of epicuticular waxes was found on the leaves under the elevated condition. Meanwhile, the abaxial leaf surface of Suwon poplar under an ambient condition was covered with long trichomes. The leaves under the elevated condition possessed a higher amount of long trichomes than those under the ambient condition. These results suggest that the two poplar species may change their leaf surface structures under the elevated air temperature and $\mathrm{CO}_{2}$ concentration condition for acclimation of increased photosynthesis.

Key Words: Carbon dioxide, Climate change, Poplar, Trichome, Wax

\section{INTRODUCTION}

The world's climate has become warmer and will change further at an unprecedented rate (Sturrock et al., 2011). In the fourth Intergovernmental Panel on Climate Change (IPCC) assessment report (Pachauri \& Reisinger, 2008), increasing carbon dioxide $\left(\mathrm{CO}_{2}\right)$ was noted as the most conspicuous component, since it had increased from $280 \mathrm{ppm}$ before the onset of the Industrial Revolution to $379 \mathrm{ppm}$ in 2005 (Günthardt-Goerg \& Arend, 2013). Because atmospheric $\mathrm{CO}_{2}$ is expected to reach $700 \mathrm{ppm}$ during this century and remain elevated for several centuries, plant responses to elevated $\mathrm{CO}_{2}$ will be an important determinant of many ecological interactions into the foreseeable future (Karowe \& Grubb, 2011). Even the most optimistic estimates of the effects of contemporary fossil fuel use suggest that mean global temperature will rise by a minimum of $2^{\circ} \mathrm{C}$ before the end of this century and that $\mathrm{CO}_{2}$ emissions will affect climate for tens of thousands of years (Ash et al., 2013).

Plant morphogenesis is governed by the effects of environmental conditions superimposed on genetic constraints (Pritchard et al., 1999). Large increases in leaf area, changes in shape and initiation of epidermal cells have been recorded in tree species in response to elevated $\mathrm{CO}_{2}$ concentration (Ferris et al., 2002). An elevated $\mathrm{CO}_{2}$ concentration $(650 \mathrm{ppm})$ decreased mean leaf area, but increased starch accumulation, thus resulting in a higher specific dry mass of leaves than that under the atmospheric $\mathrm{CO}_{2}$ concentration (360 ppm) (Ro et al., 2001). The abaxial stomatal density and leaf area of bluebunch wheatgrass were also plastic in response to climate manipulations (Fraser et al., 2009).

Poplars include aspens (species of Populus, section Populus), cottonwoods (species of sections of Tacamahaca Spach and Aigeiros Duby), and various hybrids among and within sections (Rottmann et al., 2000). Poplars are fast-growing, deep-rooted, and easily propagated, making them good candidates for phytoremediation together with willows

(a) This is an open-access article distributed under the terms of the Creative Commons Attribution Non-Commercial License (http://creativecommons.org/licenses/by-nc/3.0) which permits unrestricted noncommercial use, distribution, and reproduction in any medium, provided the original work is properly cited.

Copyrights () 2013 by Korean Society of Microscopy 
(Robinson et al., 2000). In particular, Liriodendron tulipifera (yellow or tulip poplar) has been considered as a major planting species by the Korea Forest Service with extensive planting in Korea to produce woody biomass (Kim et al., 2011a). Populus tomentiglandulosa (Suwon poplar) can be used for short duration plants as woodchip fertilizer (Ahmed et al., 2011). A better understanding of plant response to climate change will be necessary in conservation of natural resources and optimizing the growth and productivity of future managed crop production (Günthardt-Goerg \& Arend, 2013). Here, we report the effects of elevated air temperature and $\mathrm{CO}_{2}$ concentration on the leaf surface structures of poplars.

\section{MATERIALS AND METHODS}

\section{Plant Materials under Controlled Environment Conditions}

Two kinds of poplars were used in this study: (1) L. tulipifera and (2) P. tomentiglandulosa. Cuttings of each poplar were exposed to elevated air temperatures at $27 / 22^{\circ} \mathrm{C}$ (day/ night)and $\mathrm{CO}_{2}$ concentrations at $770 / 790 \mathrm{ppm}$ (day/night) in plant growth chambers (DLH-350S; Dooyoung Ensys, Goyang, Korea) for three months. An ambient condition at $22 / 17^{\circ} \mathrm{C}$ and $380 / 400$ ppm was also included as a control. The photosynthetic photon flux density was maintained at $280 \mu \mathrm{mol} \mathrm{m} \mathrm{m}^{-2}$, and the relative humidity was $75 \%$ in the chambers throughout the period. The plants were watered two or three times per week.

\section{Field Emission Scanning Electron Microscopy}

Mature leaves were collected from the middle part of the plant height for microscopy. To preserve epicuticular wax structures, detached leaves were kept in paper envelopes and dried at room temperature at least for one month (Kim et al., 2011b). Leaf fragments (approximately $5 \times 5 \mathrm{~mm}^{2}$ ) were excised from the middle portion of the detached leaves from each poplar using scissors. Both the adaxial (upper) and abaxial (lower) leaf surfaces were mounted on a metal stub and coated with
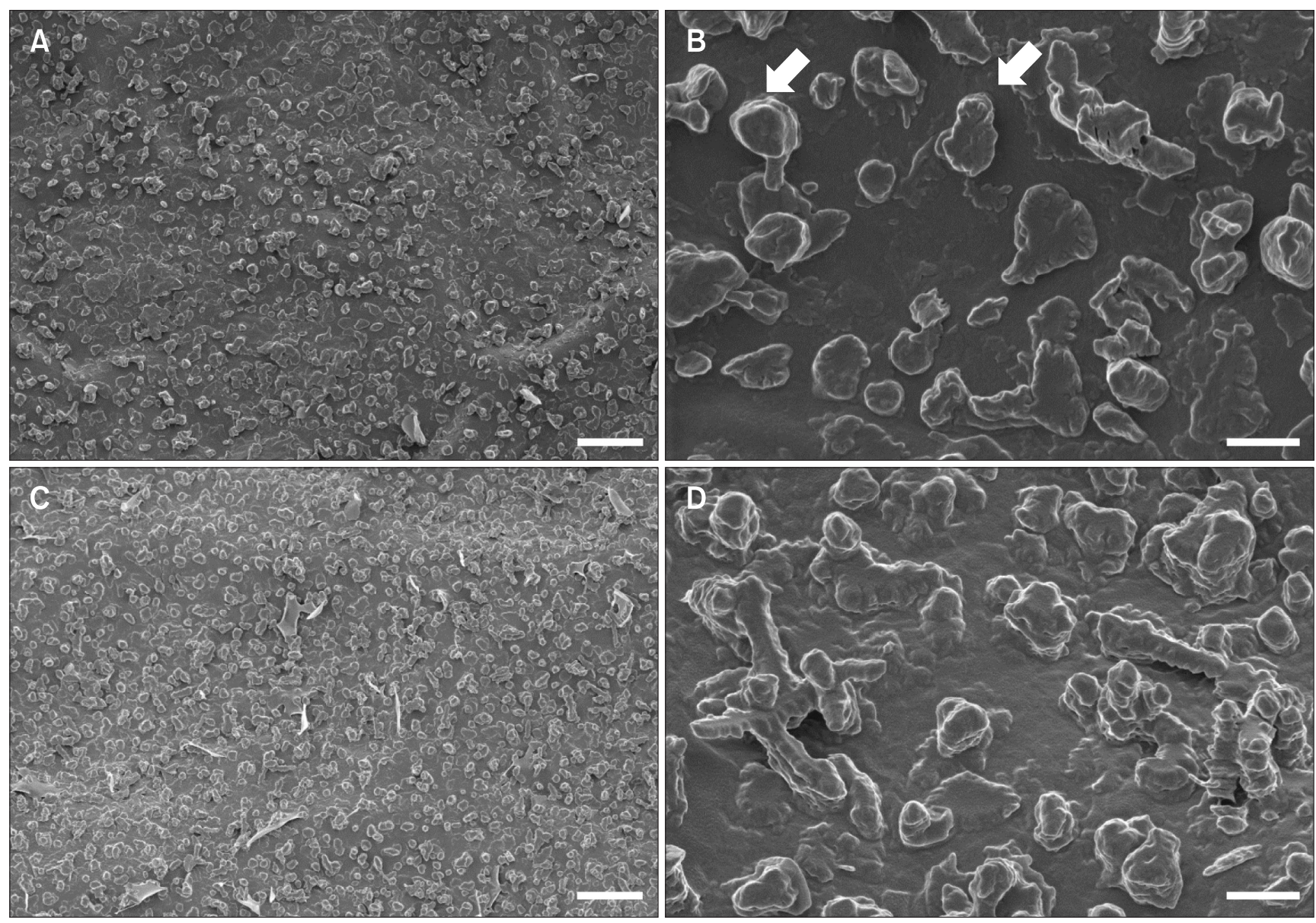

Fig. 1. Field emission scanning electron micrographs of the adaxial leaf surface of Liriodendron tulipifera. (A) A leaf under the ambient condition. No stomata were found on the surface (scale bar=5 $\mu \mathrm{m}$ ). (B) Higher magnification of the leaf surface under the ambient condition. Epicuticular waxes (arrows) were randomly distributed on the epidermis (scale bar=1 $\mu \mathrm{m}$ ). (C) A leaf under the elevated condition (scale bar=5 $\mu \mathrm{m}$ ). (D) Higher magnification of the leaf surface under the elevated condition. The waxes were granule or irregularly shaped (scale bar=1 $\mu \mathrm{m})$. 
platinum using a sputter-coater (SCD 005; BAL-TEC, Balzers, Liechtenstein). They were examined with a field emission scanning electron microscope (Supra 55VP; Carl Zeiss, Oberkochen, Germany) operated at an accelerating voltage of $2 \mathrm{kV}$. Secondary electron signals were detected using an axial in-lens detector. The nomenclature of the micromorphology of plant waxes was adopted from Barthlott et al. (1998).

\section{RESULTS}

\section{Yellow Poplar}

The adaxial leaf surface of yellow poplar under the ambient condition was overall smooth and covered with epicuticular waxes (Fig. 1A). No stomata were present on the adaxial leaf surface. At higher magnifications, epicuticular waxes appeared to be randomly distributed on the adaxial leaf surface (Fig. 1B). Granule or irregularly shaped waxes ranged from approximately $200 \mathrm{~nm}$ to $2 \mu \mathrm{m}$ in diameter. Under the elevated condition, the adaxial leaf surface of yellow poplar was almost similar to that under the ambient condition (Fig. 1C). Neither trichomes nor stomata were found on the adaxial leaf surface. Irregularly shaped waxes were also evident on the adaxial leaf surface (Fig. 1D).

Meanwhile, the abaxial leaf surface of yellow poplar under the ambient condition was rather undulating (Fig. 2A). Stomata were found on the abaxial leaf surface. It was common to observe epicuticular waxes on the epidermis (Fig. 2B). However, no distinct waxes were detected on the stomatal guard cells. Compared with that under the ambient condition, the abaxial leaf surface of yellow poplar under the elevated condition appeared to have more epicuticular waxes (Fig. $2 \mathrm{C}$ ). Although the abaxial leaf surface of yellow poplar under the elevated condition was highly studded with waxes, the stomatal guard cells did not have distinct waxes (Fig. 2D). At higher magnifications, the fine structure of epicuticular waxes could be revealed (Fig. 3A). Rodlets had a variable length and diameter. They were almost perpendicularly attached to the leaf surface (Fig. 3B). Some waxes were
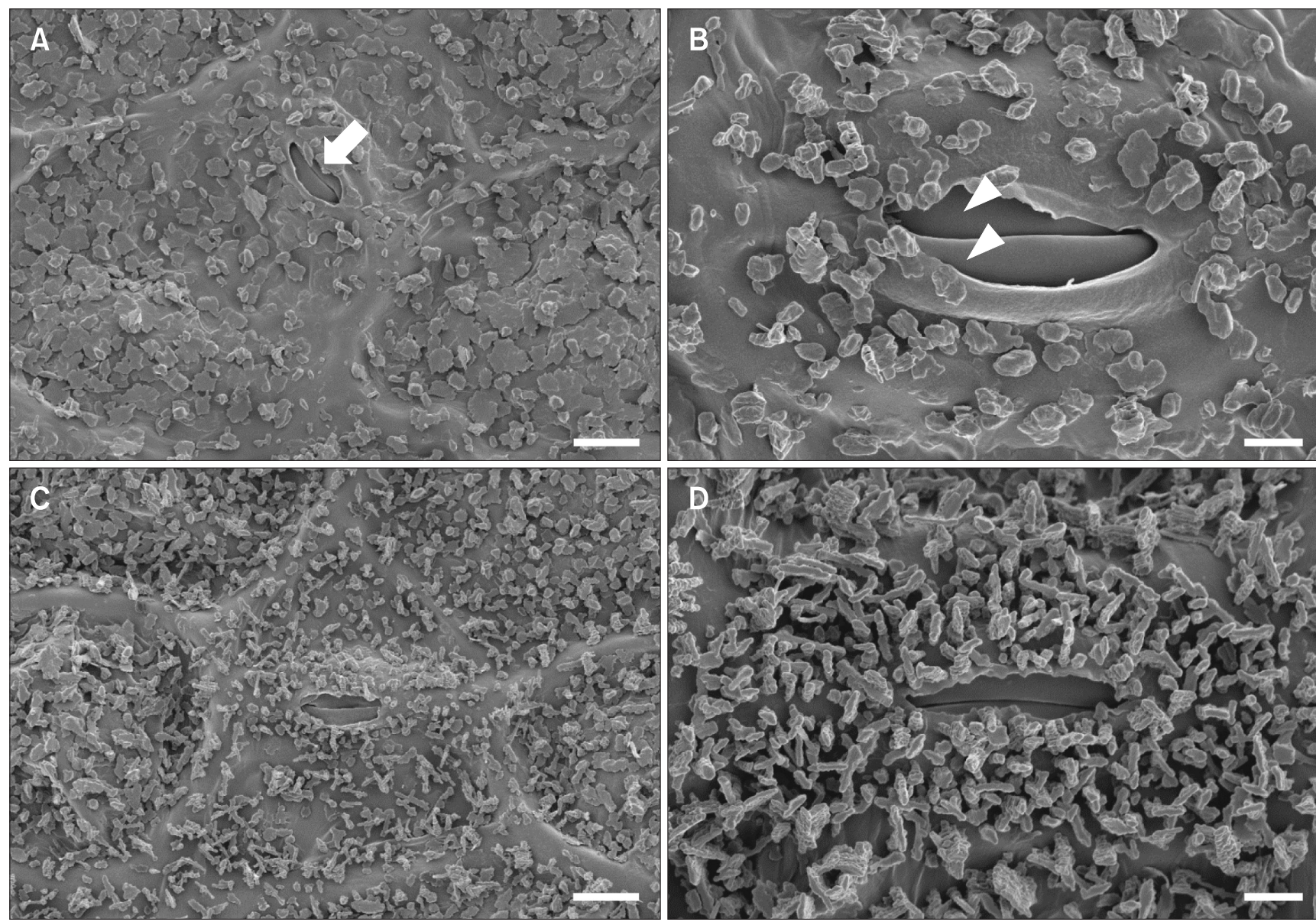

Fig. 2. Field emission scanning electron micrographs of the abaxial leaf surface of Liriodendron tulipifera. (A) A leaf under the ambient condition. An arrow indicated a stoma on the surface (scale bar=5 $\mu \mathrm{m}$ ). (B) Higher magnification of a stoma under the ambient condition. Arrowheads indicated stomatal guard cells (scale bar=2 $\mu \mathrm{m}$ ). (C) A leaf under the elevated condition (scale bar=5 $\mu \mathrm{m}$ ). (D) Higher magnification of a stoma under the elevated condition. The increase in the density of epicuticular waxes was apparent on the epidermis, compared with (B) (scale bar=2 $\mu \mathrm{m})$. 

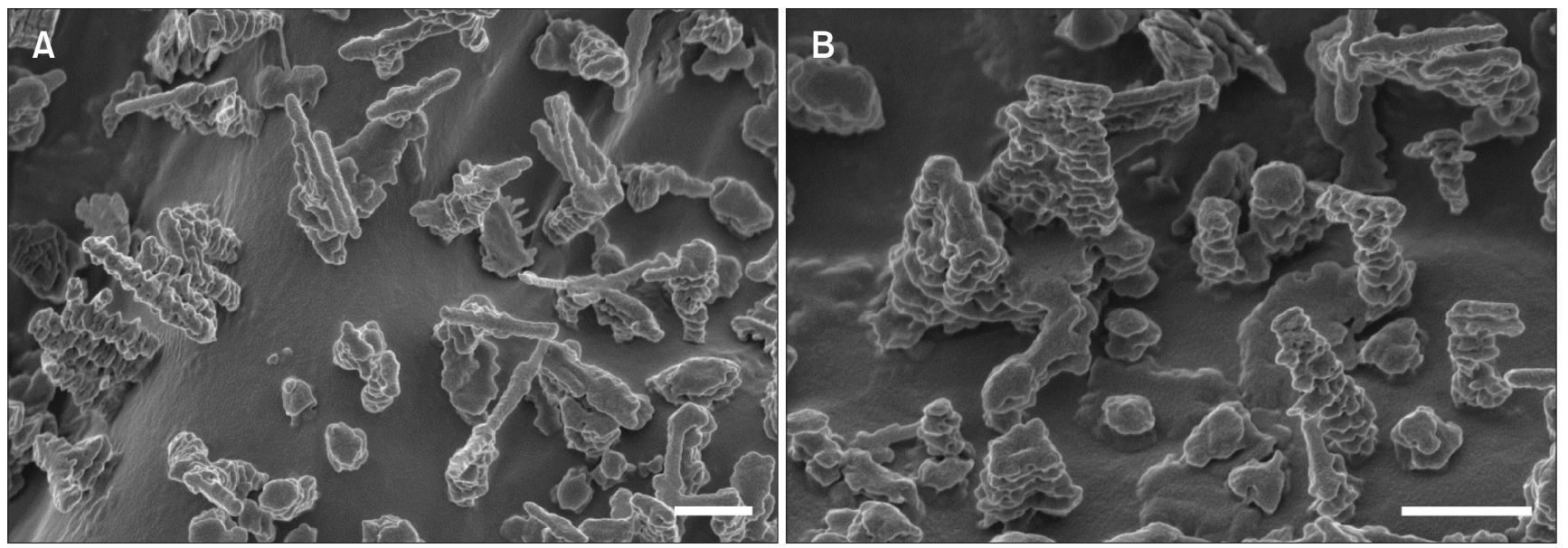

Fig. 3. Field emission scanning electron micrographs of the abaxial leaf surface of Liriodendron tulipifera under the elevated condition. (A) Epicuticular waxes. (B) Higher magnification of epicuticular waxes. With varying dimensions, rodlets were perpendicularly attached to the epidermis. Scale bars=1 $\mu \mathrm{m}$.
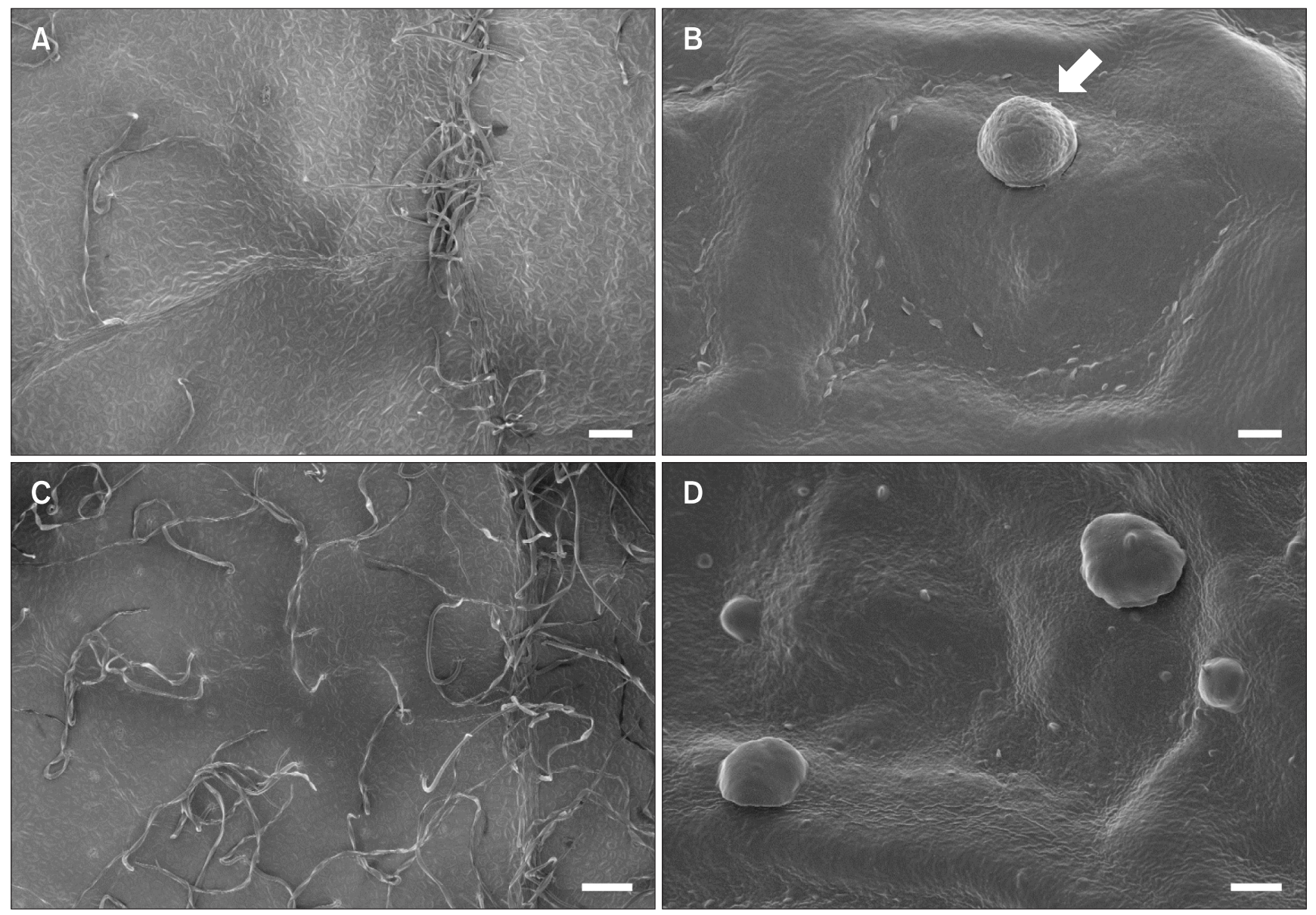

Fig. 4. Field emission scanning electron micrographs of the adaxial leaf surface of Populus tomentiglandulosa. (A) A leaf under the ambient condition. No stomata were found on the surface (scale bar $=100 \mu \mathrm{m}$ ). (B) Higher magnification of the leaf surface under the ambient condition. An arrow indicated a peltate trichome (scale bar=2 $\mu \mathrm{m}$ ). (C) A leaf under the elevated condition. The increase in the density of long trichomes was apparent on the epidermis, compared with (A) (scale bar=100 $\mu \mathrm{m})$. (D) Higher magnification of the leaf surface under the elevated condition. There was an increase in the density of peltate trichomes (scale bar $=2 \mu \mathrm{m}$ ). 
merged and plate-like in shape. No distinct differences in morphology of the epicuticular waxes were observed between the two conditions.

\section{Suwon Poplar}

The adaxial leaf surface of Suwon poplar under the ambient condition had long trichomes, but not stomata (Fig. 4A). The trichomes were mainly observed on the central veins on the epidermis. At higher magnifications, round to peltate trichomes were often found on the surface (Fig. 4B). They were approximately $5 \mu \mathrm{m}$ in diameter. Under the elevated condition, the adaxial leaf surface of Suwon poplar had more long trichomes than that under the ambient condition (Fig. 4C). They were prevalently distributed on the epidermis as well as on the central veins. An increase in the peltate trichomes was noted on the adaxial leaf surface of Suwon poplar under the elevated condition (Fig. 4D).

Furthermore, stomata were found on the adaxial leaf surface of Suwon poplar under the elevated condition (Fig. 5A). Transitions of epidermal cells to stomatal complexes occurred on the surface. The initial stages of stomatal formation were characterized by protrusion of the epidermis (Fig. 5B). With
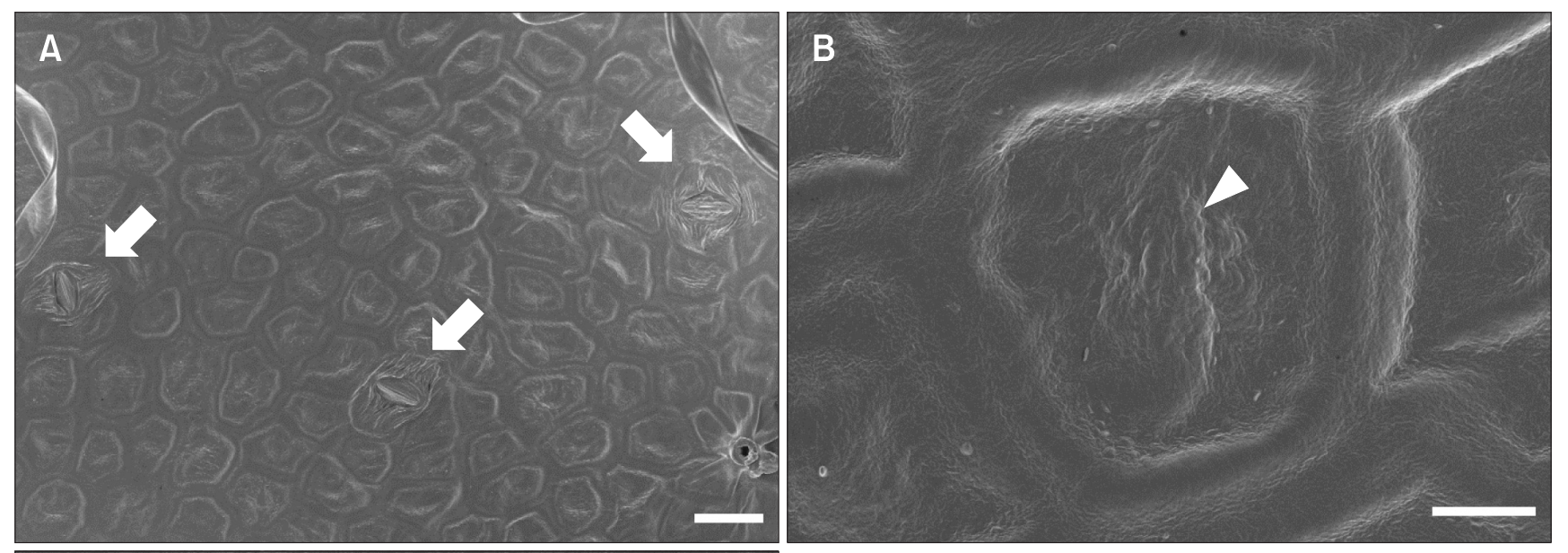

the formation of stomatal guard cells, there was a cuticular folding on the epidermis (Fig. 5C). Stomatal guard cells were approximately $10 \mu \mathrm{m}$ in width and $20 \mu \mathrm{m}$ in length.

The abaxial leaf surface of Suwon poplar under the ambient condition was covered with long trichomes (Fig. 6A). Stomata were found on the abaxial leaf surface (Fig. 6B). Suwon poplar under the elevated condition had more profuse long trichomes on the abaxial leaf surface than that under the ambient condition (Fig. 6C). The higher growth of trichomes under the elevated condition was also apparent at higher magnifications than that under the ambient condition (Fig. 6D).

\section{DISCUSSION}

This study demonstrated the leaf surface changes of poplars due to elevated air temperature and $\mathrm{CO}_{2}$ concentration by electron microscopy. Different responses to the elevated condition were found according to the tree species and leaf surface. No distinct differences were observed on the adaxial leaf surface of yellow poplar between the two conditions. The glabrate epidermis and wax granules on the adaxial

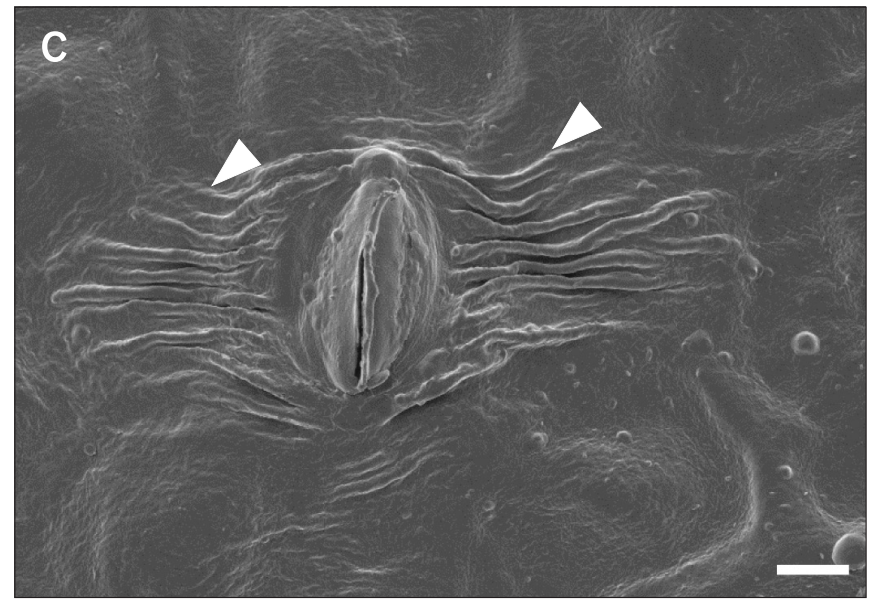

Fig. 5. Field emission scanning electron micrographs of the adaxial leaf surface of Populus tomentiglandulosa under the elevated condition. (A) A leaf under the ambient condition. Arrows indicated stomata (scale bar $=20$ $\mu \mathrm{m}$ ). (B) Initiation of stomatal formation. The epidermal protrusion (an arrowhead) was discerned on the surface (scale bar=5 $\mu \mathrm{m}$ ). (C) A fully developed stomata. There was a cuticular folding (arrowheads) around the stoma (scale bar $=5 \mu \mathrm{m})$. 

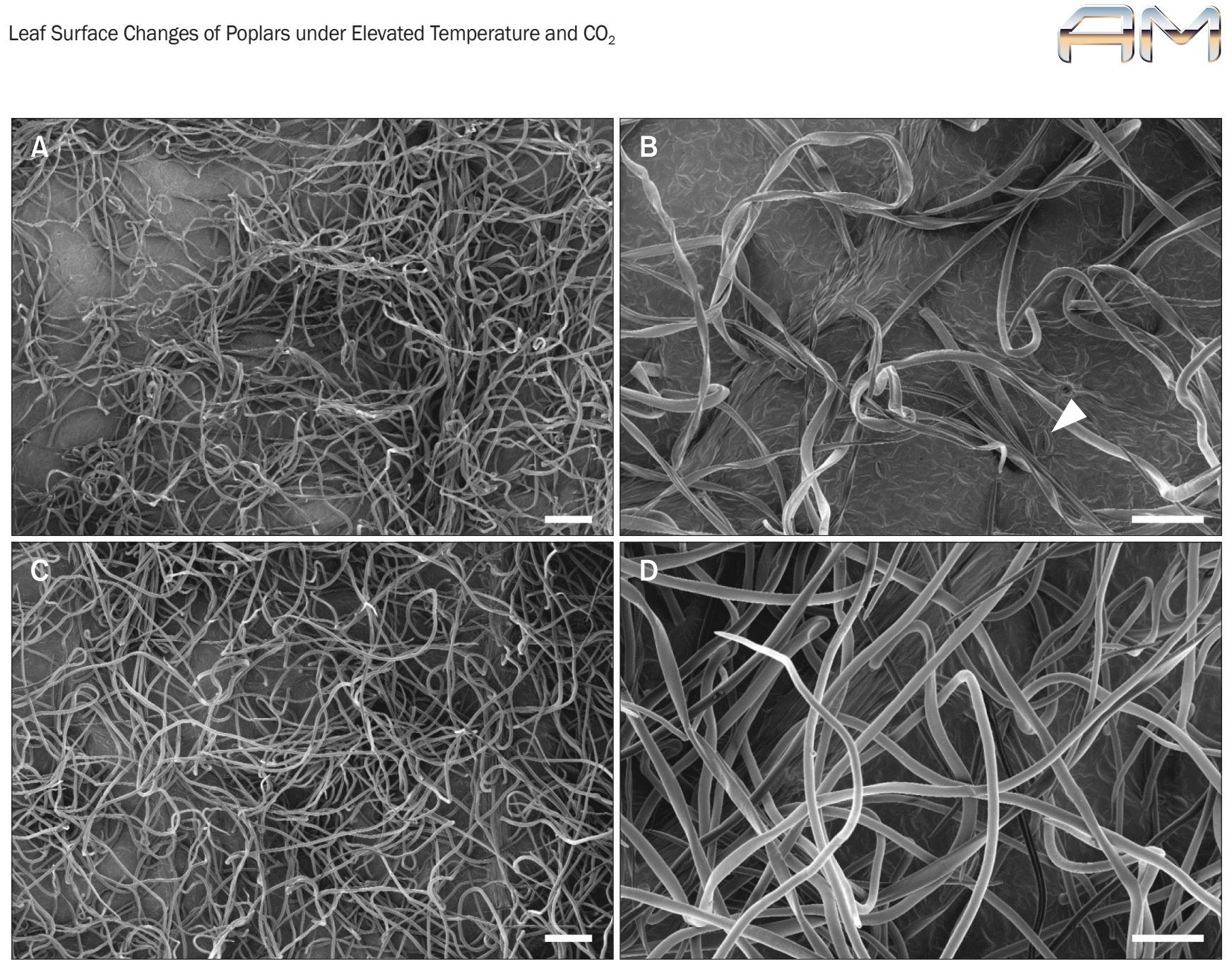

Fig. 6. Field emission scanning electron micrographs of the abaxial leaf surface of Populus tomentiglandulosa. (A) A leaf under the ambient condition. Long trichomes were prevalent on the surface (scale bar=100 $\mu \mathrm{m}$ ). (B) Higher magnification of the leaf surface under the ambient condition. An arrowhead indicated a stoma (scale bar $=50 \mu \mathrm{m}$ ). (C) A leaf under the elevated condition. It was common to observe profuse trichomes on the surface (scale bar=100 $\mu \mathrm{m})$. (D) Higher magnification of the leaf surface under the elevated condition. The increase in the density of long trichomes was apparent on the epidermis, compared with (B) (scale bar=50 $\mu \mathrm{m})$.

leaf surface of yellow poplar were in agreement with those previously reported (Haines et al., 1985). However, the yellow poplar under the elevated condition showed more pronounced accumulation of epicuticular waxes on the abaxial leaf surface than that under the ambient condition. Through the intense coverage of epidermis by epicuticular waxes, it is likely that the yellow poplar could reduce water loss from transpiration and improve water use efficiency for acclimation of increased photosynthesis under the elevated concentration. The short-term exposure of yellow poplar to the elevated air temperature and $\mathrm{CO}_{2}$ concentration in this study was sufficient to alter leaf surface structures. According to the classification of plant epicuticular waxes by Barthlott et al. (1998), the waxes on the abaxial leaf surface of yellow poplar under the two conditions could be referred to as transversely ridged rodlets. Morphologically similar waxes have been also reported from another species of the same genus Liriodendron (Ensikat et al., 2006) and other taxa
(Meusel et al., 1999). To our knowledge, this is the first report on the morphology of the epicuticular waxes of yellow polar by high-resolution scanning electron microscopy.

Suwon poplar also showed leaf surface changes due to the elevated condition. The adaxial leaf surface of Suwon poplar possessed stomata under the elevated condition. One of the most obvious effects of elevated air temperature and $\mathrm{CO}_{2}$ concentration on trees would be the increased rate of photosynthetic carbon fixation. It is possible that the increased photosynthesis under the elevated condition would promote Suwon poplar to form stomata on the adaxial epidermis as well as on the abaxial leaf surface. Since the periodic watering prevented the trees from wilting in this study, the trees could stimulate the formation of stomata for increased photosynthesis under the elevated condition.

Furthermore, the increased density of long trichomes on both the adaxial and abaxial leaf surfaces was apparent under the elevated condition. A similar phenomenon was observed in a 
previous study (Kim et al., 2002) where the trichome density of Suwon poplar was higher in waste landfills than that in nursery. These results suggest that the Suwon poplar showed adaptive phenotypic plasticity to the particular environments such as the elevated condition or waste landfills. It is obvious that the increased trichomes would contribute to the reduced water loss from the epidermis, resulting in tree survival. The implications of increased peltate trichomes with the elevated condition need to be elucidated in further studies.

A scenario of future climate change was simulated to predict the morphological response of poplars to elevated air temperature and $\mathrm{CO}_{2}$ concentration. Since the treatments of elevated air temperature and $\mathrm{CO}_{2}$ concentration were performed simultaneously in this study, the effects of each factor on the trees could not be elucidated. Given the observed changes in leaf surface structures under the elevated condition, the adaptive phenotypic plasticity of the poplars to future climate change might be expected in the forest stand with water resources available to tree growth.

\section{CONCLUSIONS}

Leaf surface structures were plastic in morphological response to possible conditions under climate change. The most striking changes due to elevated air temperature and $\mathrm{CO}_{2}$ concentration included the increased accumulation and formation of the epicuticular waxes, trichomes, and stomata on the leaf surface of poplars. These responses represent the adaptive phenotypic plasticity of the tree species to the elevated condition for acclimation of increased photosynthesis with water resources available to tree growth.

\section{REFERENCES}

Ahmed S A, Kim J I, Park K M, and Chun S K (2011) Ammonium nitrateimpregnated woodchips: a slow-release nitrogen fertilizer for plants. J. Wood Sci. 57, 295-301.

Ash C, Culotta E, Fahrenkamp-Uppenbrink J, Malakoff D, Smith J, Sugden A, and Vignieri S (2013) Once and future climate change. Science 341, 472-473.

Barthlott W, Neinhuis C, Cutler D, Ditsch F, Meusel I, Theisen I, and Wilhelmi H (1998) Classification and terminology of plant epicuticular waxes. Bot. J. Linn. Soc. 126, 237-260.

Ensikat H J, Boese M, Mader W, Barthlott W, and Koch K (2006) Crystallinity of plant epicuticular waxes: electron and X-ray diffraction studies. Chem. Phys. Lipids. 144, 45-59.

Ferris R, Long L, Bunn S M, Robinson K M, Bradshaw H D, Rae A M, and Taylor G (2002) Leaf stomatal and epidermal cell development: identification of putative quantitative trait loci in relation to elevated carbon dioxide concentration in poplar. Tree Physiol. 22, 633-640.

Fraser L H, Greenall A, Carlyle C, Turkington R, and Friedman C R (2009) Adaptive phenotypic plasticity of Pseudoroegneria spicata: response of stomatal density, leaf area and biomass to changes in water supply and increased temperature. Ann. Bot. 103, 769-775.

Günthardt-Goerg M S and Arend M (2013) Woody plant performance in a changing climate. Plant Biol. 15(Suppl 1), 1-4.

Haines B L, Jernstedt J A, and Neufeld H S (1985) Direct foliar effects of simulated acid rain II. Leaf surface characteristics. New Phytol. 99, 407-416.

Karowe D N and Grubb C (2011) Elevated $\mathrm{CO}_{2}$ increases constitutive phenolics and trichomes, but decreases inducibility of phenolics in Brassica rapa (Brassicaceae). J. Chem. Ecol. 37, 1332-1340.

Kim H Y, Lee J W, Jeffries T W, and Choi I G (2011a) Response surface optimization of oxalic acid pretreatment of yellow poplar (Liriodendron tulipifera) for production of glucose and xylose monosaccharides. Biores. Tech. 102, 1440-1446.
Kim K W, Cho D H, and Kim P G (2011b) Morphology of foliar trichomes of the Chinese cork oak Quercus variabilis by electron microscopy and three-dimensional surface profiling. Microsc. Microanal. 17, 461-468.

Kim P G, Kim S H, Lee S M, Lee C H, and Lee E J (2002) Adaptability to the water relations of Populus alba×P. glandulosa in 'Kimpo' waste landfills. J. Korean For. Soc. 91, 279-286.

Meusel I, Neinhuis C, Markstädter C, and Barthlott W (1999) Ultrastructure, chemical composition, and recrystallization of epicuticular waxes: transversely ridged rodlets. Can. J. Bot. 77, 706-720.

Pachauri R K and Reisinger A (2008) Climate Change 2007. Synthesis Report. Contribution of Working Groups I, II and III to the Fourth Assessment Report (IPCC, Geneva).

Pritchard S G, Rogers H H, Prior S A, and Peterson C M (1999) Elevated $\mathrm{CO}_{2}$ and plant structure: a review. Glob. Change Biol. 5, 807-837.

Ro H M, Kim P G, Lee I B, Yiem M S, and Woo S Y (2001) Photosynthetic characteristics and growth responses of dwarf apple (Malus domestica Borkh. cv. Fuji) saplings after 3 years of exposure to elevated atmospheric carbon dioxide concentration and temperature. Trees 15, 195-203.

Robinson B H, Mills T M, Petit D, Fung L E, Green S R, and Clothier B E (2000) Natural and induced cadmium-accumulation in poplar and willow: implications for phytoremediation. Plant Soil 227, 301-306.

Rottmann W H, Meilan R, Sheppard L A, Brunner A M, Skinner J S, Ma C, Cheng S, Jouanin L, Pilate G, and Strauss S H (2000) Diverse effects of overexpression of $L E A F Y$ and PTLF, a poplar (Populus) homolog of LEAFY/FLORICAULA, in transgenic poplar and Arabidopsis. Plant J. 22, 235-245.

Sturrock R N, Frankel S J, Brown A V, Hennon P E, Kliejunas J T, Lewis K J, Worrall J J, and Woods A J (2011) Climate change and forest diseases. Plant Pathol. 60, 133-149. 